\title{
Source Mechanism of February 4, 1965, Rat Island Earthquake
}

\author{
Francis T. Wu \\ Department of Geology, State University of New York \\ Binghamton, New York 19901 \\ Hiroo KANAMORI ${ }^{1}$ \\ Earthquake Research Institute, University of Tokyo \\ Tokyo, Japan
}

\begin{abstract}
The Rat Island earthquake of February 4, 1965 (origin time $05 \mathrm{~h} 01 \mathrm{~m} 21.8 \mathrm{~s}, h=40 \mathrm{~km}$ ), is one of the largest earthquakes recorded in recent years. On the basis of the radiation patterns and the amplitudes of the great circle Rayleigh and Love waves, the earthquake is found to have the following characteristics: fault plane dip, $18^{\circ}$; fault plane dip direction, $\mathrm{N}^{\circ} 9^{\circ} \mathrm{E}$; rupture propagation direction, $\mathrm{N5} 1^{\circ} \mathrm{W}$; rupture propagation velocity, $4.0 \mathrm{~km} / \mathrm{sec}$; fault length, $500 \mathrm{~km}$; moment, $1.4 \times 10^{29}$ dynes $\mathrm{cm}$; stress drop, 30 bars; and average dislocation, 2.5 meters. It is interesting to observe that the attitude of the fault plane and the general features of this earthquake are similar to those of the 1963 Kurile earthquake (Kanamori, 1970a) and the 1964 Alaskan earthquake (Kanamori, 1970b). The first 35 sec of $P$ waves were also well recorded at many stations. The wave forms suggest a multiple-event nature of the earthquake for at least the initial 35 sec. By using the relative location method, the events were located progressively south of the initial hypocenter. It seems plausible that the earthquake started off at depth, first propagated southward, and then westward along the Aleutian arc. Owing to the long-period nature of the surface waves, only the average feature of the fault is seen, and $P$ waves reveal some of the detailed initial behavior.
\end{abstract}

In the period 1962-1965, during which the World-Wide Standard Seismograph Network (WWSSN) operated with $T_{0}=30 \mathrm{sec}$ and $T_{s}=100 \mathrm{sec}$, several large shallow earthquakes occurred in the circum-Pacific island arc chain. With $T_{0}=30 \mathrm{sec}$, enough long-period $(T>$ $150 \mathrm{sec}$ ) waves appear on the records for a study of the dynamics of faulting of these large events. Kanamori [1970a, b] has studied the 1963 Kurile earthquake $(M=8.2)$ and the 1964 Alaskan earthquake $(M=8.5)$. Both studies reveal the shallow thrust nature of the events and the fact that rupture propagates more or less along the strike directions. Besides, the studies also clearly demonstrate the relative 'size' of these earthquakes: the moment of the Alaskan event is approximately 10 times larger than that of the Kurile event.

\footnotetext{
${ }^{1}$ Now at Seismological Laboratory, California Institute of Technology, Pasadena, California 91109.
}

Copyright (C) 1973 by the American Geophysical Union.
Undoubtedly, the February 4, 1965, Rat Island earthquake is one of the major events. It excited large-amplitude free oscillations of the earth [Nowroozi, 1966], and at many stations with low magnification $(\times 750)$ one could see well-recorded $R_{6}$ and $G_{8}$, and it is not uncommon to see $R_{\text {a }}$ on many of the WWSSN records. The aftershock area extends over a distance of approximately $600 \mathrm{~km}$ along the Aleutian arc, and there are more than 10 aftershocks with magnitudes higher than 6 . It would be therefore important to know the source mechanism and to see whether this earthquake shares some common characteristics of the two already studied. Stauder [1968b] worked out the partial focal mechanism solution for the main shock and complete solutions for many of the aftershocks. These data will assist us in choosing our preliminary trial solutions.

The waves used for the surface wave source mechanism for this earthquake are mainly $G_{5}$ and $R_{5}$. The method of analysis is much the same as that used earlier by Kanamori [1970a, 
b]. The frequency content of these waves is concentrated in the range $0.002-0.01$ cycle (corresponding to $500-100 \mathrm{sec}$ ). As a consequence, the detailed behavior, with a time scale of the order of $50 \mathrm{sec}$ or less, will not be revealed by these waves at all. What we observe are the average properties of the faulting process.

In addition to the source mechanism study, the method above also presents information that enables us to determine the relative magnitude of large earthquakes. This ability is rather important. For large earthquakes the magnitude is always somewhat ambiguous, because a typical $P$ wave usually consists of a group of pulses, and the concept of magnitude determination in this case breaks down; the long-period surface waves effectively integrate these individual events and differentiate very well the relative magnitude of the large events.

This earthquake has a U.S. Coast and Geodetic Survey (USCGS) $m_{b}=6.0$ but a surface wave magnitude of about $73 / 4$. For the 1964 Alaskan earthquake $m_{b}=8.5$ and $M_{s}:=8.4$ 83/4 (USCGS Seismological Bulletin MSI 279), and for the 1963 Kurile earthquake $M_{s}=73 / 4$ 81/2 (USCGS Seismological Bulletin MSI 274; no $m_{b}$ value published). The $m_{b}$ magnitudes are based on a particular part of a complicated $P$ wave train, and $M$, is based on a particular part ('20-sec Rayleigh waves') of a dispersed surface wave; neither is representative of a large earthquake. On the other hand, if we measure magnitudes by waves with periods commensurate with the source-time duration, we have effectively summed the multiple events and avoided the lateral refraction and other problems associated with the 20 -sec waves.

For this particular earthquake we were able to use $P$ waves to study the initial multiple source event behavior of the source. Similar analyses have been carried out by Wyss and Brune [1967], among others. They used shortperiod (mainly Wiechert) records and concluded that the Alaskan earthquake can be represented as a multiple event. That a large earthquake consists of a number of small events is only natural, when the diverse nature of frictional characteristics along the entire fault zone spanning hundreds of kilometers is considered. We are able to follow the details of source development in the first $35 \mathrm{sec}$ or so.

\section{$P$ Waves and Initial Source Behavior}

For most large earthquakes the long-period $P$ waves show complicated groups of pulses. The amplitude relations of these pulses vary from station to station, and the time intervals between them do not bear any relation to the known $P$ phases refracted and reflected at the various discontinuities inside the earth. These pulses are therefore most probably the result of a complicated source-time function.

Some examples of the long- and short-period $P$ waves for the Rat Island mainshock are shown in Figure 1. With the exception of those recorded at United States continental stations, long-period $P$ waves are found to correlate very well at stations of all distances and azimuth angles. The exceptions are probably due to the closeness of those stations to the radiation pattern minimum. In Figure 1 we can see that there are usually identifiable short-period $P$ phases associated with a long-period pulse; the reverse is not true. The station-to-station correlation of the short-period records is very poor. In the following, the long-period $P$ waves are the ones used for analyses. In Figure 2 the differential travel times $t_{p t}-t_{p}$, where $t_{p t}$ is the time of the $i$ th arrival and $t_{p}$ is that of the first motion, are plotted as a function of azimuthal angle.

To locate the secondary events, one can use a simple least squares procedure [Fukao, 1972]. Assume that the individual events are separated in time by $\tau_{0}$ and in space by $\delta \Delta$ in a certain direction; then at the $i$ th station we have

$$
\delta t_{1}=\tau_{0}-\left[\left(\delta \Delta / \nu_{p}\right) \cos \theta_{2}\right]
$$

where $\delta t_{t}$ is the differential time between two arrivals, $v_{p}$ is the $P$ wave velocity, and $\theta_{1}$ is the angle between the line element connecting the two hypocenters and the ray leaving the first hypocenter. By assuming a direction of the line element, one can compute the $\theta_{\mathfrak{l}}$ and then use a linear regression procedure to find $r_{0}$ and $\delta \Delta$. The direction of the line element is given by the azimuth $\phi$ measured from the north and the dip angle $D$. The method to determine the best set of $\tau_{0}$ and $\delta \Delta$ values consists of varying the direction of the line element until the minimums in standard error of the estimation of the distance $S$, or standard deviation of the time $\epsilon$, can be identified. It was found that the azimuth $\phi$ of the line element can be de- 
termined well for each $D$ assumed, but the variation of the inclination of $S$ or $\epsilon$ varies little with $D$ (Figure 3 ). The results are presented in Figure 4 and Table 1.

In both Figure 4 and Table 1, first event refers to the first multiple event after the first break and so on. Values of $\tau_{0}, \delta \Delta$, and the dip angle are determined relative to the first break. We see that $D$ is positive for the first and third events and negative for the second event; i.e., within the initial 21 sec of the earthquake, the source develops south and southeastward, the first and third events develop downdip, and the third event develops updip from the hypocenter. As we shall see in the next section, the dominant growth of the fault was westward along the Aleutian arc over a distance of 500 $\mathrm{km}$ in about $2.5 \mathrm{~min}$; the body wave results presented here indicate the initial source behavior. This southward growth may be simultaneous with the westward smoother propagation or precede the main phase of fault propagation.

\section{SuRfaCe Waves}

In this study the $R_{5}$ and $G_{5}$ are the chief waves used. Where it is necessary, $R_{4}$ and $G_{4}$ and $R_{\theta}$ and $C_{\theta}$ are used to supplement the data. The seismograms are digitized within group velocity windows of 3.7 and $3.4 \mathrm{~km} / \mathrm{sec}$ for Rayleigh waves and 4.5 and $4.3 \mathrm{~km} / \mathrm{sec}$ for Love waves and equalized in frequency domain for instrument response, attenuation, and dispersion to a standard epicentral distance of $9 \pi$ / 2 . The equalized spectra are then inverseFourier-transformed to time domain (see Kanamori $[1970 a, b]$ for details). The equalized $\boldsymbol{R}_{5}$ are presented in Figure 5 and $G_{5}$ in Figure 6. The central figures are azimuthal plots of the maximum amplitudes of these waves; these are the radiation patterns. The Rayleigh radiation pattern is apparently dipolar and shows a strong asymmetry accentuating the upper lobe and the western flanks of both the upper and the lower lobes. The Love wave pattern is not distinctly lobed, but a strong northwest accentuation is clearly indicated.

The method of interpreting these equalized waves and radiation pattern has already been expounded in detail elsewhere [Kanamori, $1970 a, b]$. It comprises two mutually related steps: (1) finding a double-couple equivalent force system that yields the correct radiation

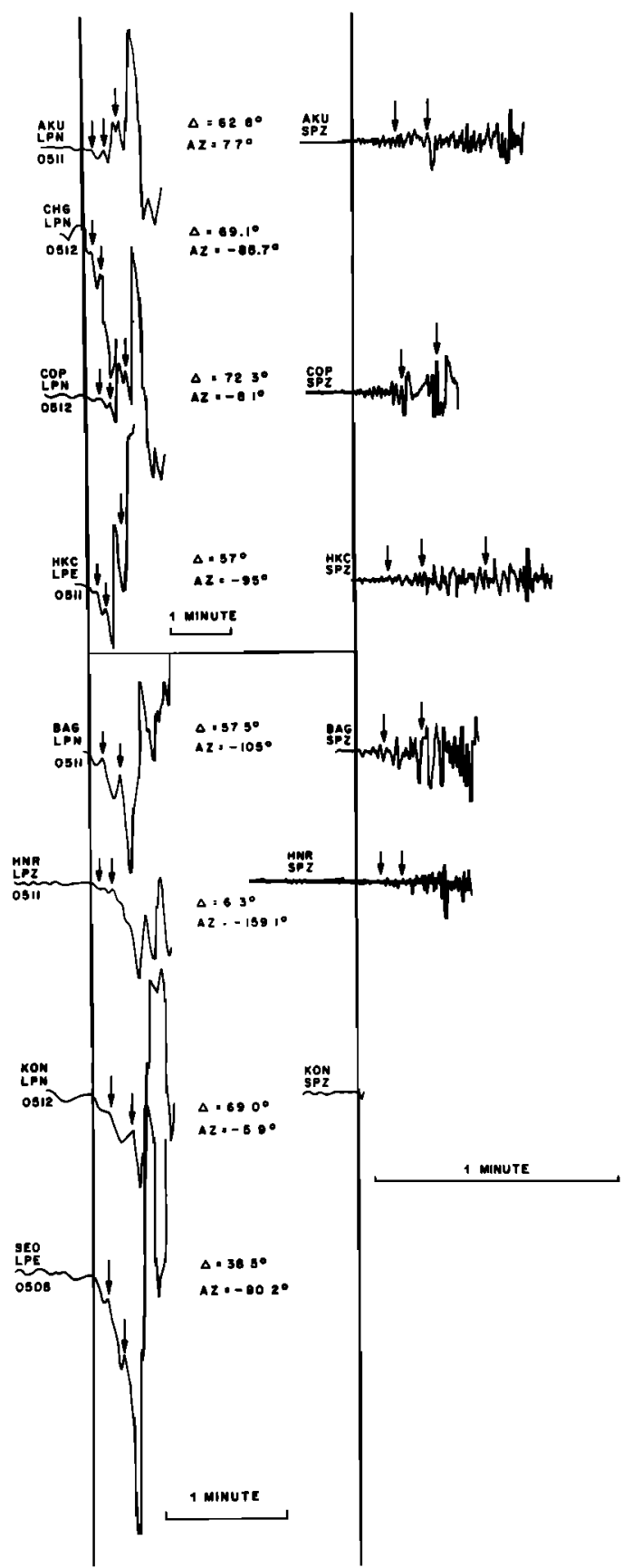

Fig. 1. Examples of long- and short-period $P$ waves recorded at several WWSSN stations. Notice that the short-period records on the right are much more complicated than the longperiod records.

pattern and the Rayleigh/Love amplitude ratio and (2) accounting for the asymmetry in the individual patterns by assuming a moving 


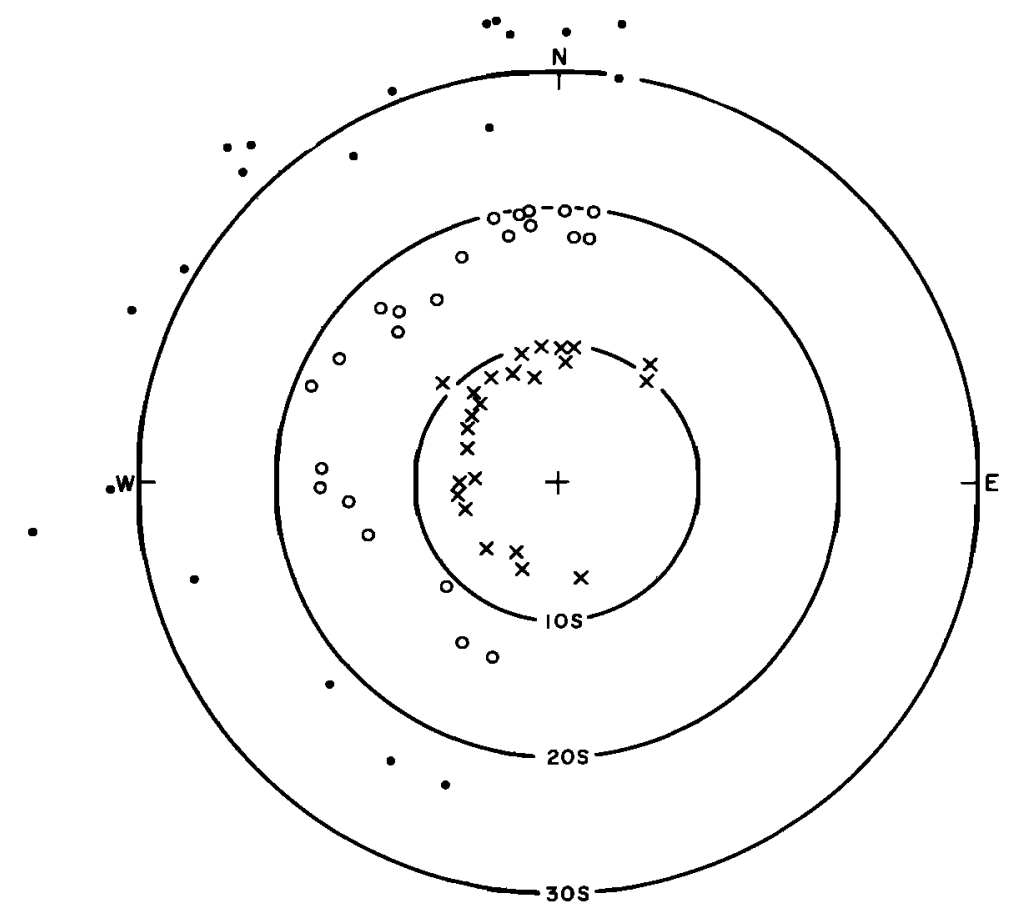

Fig. 2. Plot of $t_{p i}-t_{p}$ in seconds as a function of azimuth. Crosses indicate first events; open circles, second events; solid circles, third events.

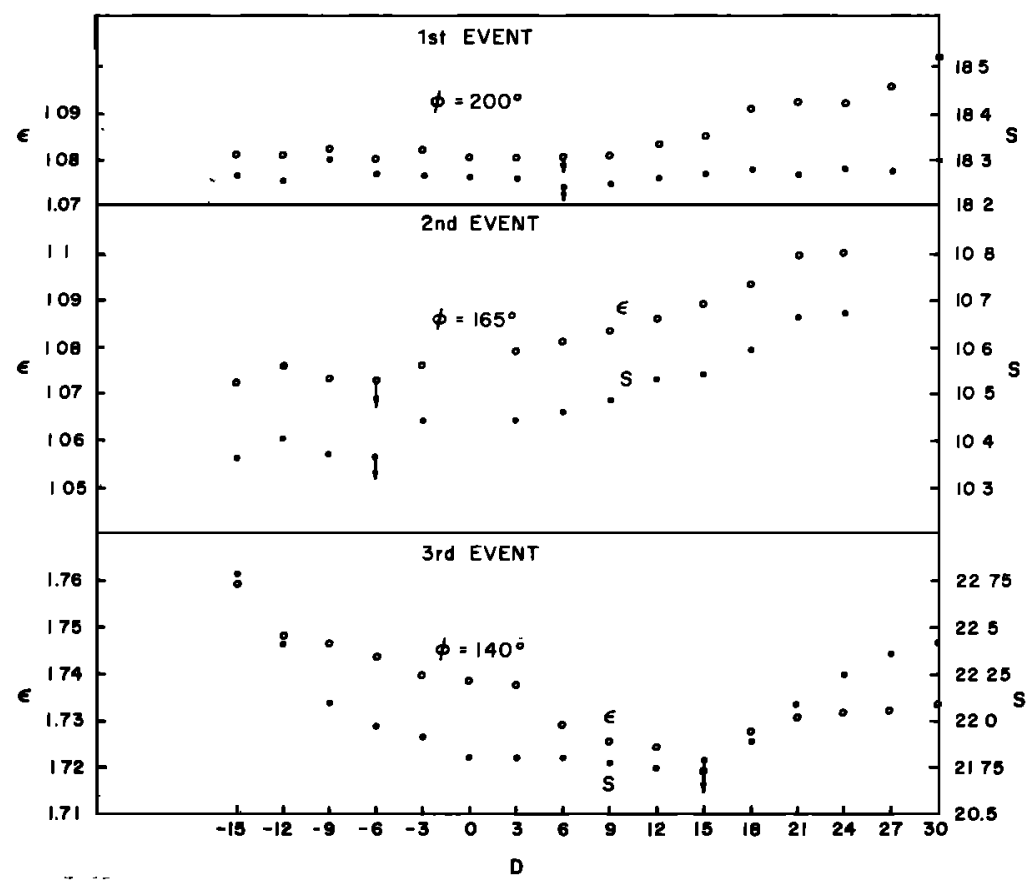

Fig. 3. Variation of $S$, standard error of $\delta \Delta$ in percent, and $\epsilon$, standard deviation in seconds, as a function of $D$, the dip of the line element. 
source model with fault length, propagation velocity and direction of faulting as parameters. We have additional guidance for this interpretation at our disposal: (1) Stauder's partial focal mechanism solutions for this main event (Figure $7 a$ ) and also complete solutions for many large aftershocks in the series and (2) spatial distribution of aftershocks (Figure $7 b$ ).

It should be noted that, because of the longperiod waves that we use here, the features derived concerning the source are average properties. Temporally, we are not able to resolve details below 100 sec. The advantage of this method is that a definite choice of fault plane can be made; in fact, for large shallow thrust earthquakes this method is the only one available to resolve the low-angle thrust plane. The best fit of the experimental data is presented in Figure $8 a$. In Figure $8 b$, theoretical radiation patterns for rupture velocities of $3,3.5$, and $5 \mathrm{~km} / \mathrm{sec}$ are compared with the pattern for $4.0 \mathrm{~km} / \mathrm{sec}$.

The results obtained indicate that the fault plane strikes $\mathrm{N} 70^{\circ} \mathrm{W}$ and dips $18^{\circ}$ in $\mathrm{N} 20^{\circ} \mathrm{E}$ direction. The auxiliary plane constrained by Stauder's [1968b] partial solution strikes $\mathrm{N} 60^{\circ} \mathrm{E}$ and dips $78^{\circ}$ in $\mathrm{S} 30^{\circ} \mathrm{E}$ direction. The fault length $L$ is about $500 \mathrm{~km}$, the rupture velocity is about $4 \mathrm{~km} / \mathrm{sec}$, and the seismic moment $M_{0}=1.4 \times 10^{20}$ dynes $\mathrm{cm}$. If we assume, from the aftershock area, the width $W$ of the fault plane to be $150 \mathrm{~km}$, the average dislocation $\langle u\rangle$ on the fault can be estimated as $\langle u\rangle=$ $M_{0} / \mu L W=2.5$ meters, where $\mu=7.0 \times 10^{11}$ dynes $/ \mathrm{cm}^{2}$ is used for an appropriate value of the rigidity. The stress drop may be estimated, according to Knopoff [1958], by $\Delta \sigma=$ $8 \mu\langle u\rangle / \pi W=30$ bars.

The fault plane solution obtained here is very similar to that obtained from the aftershocks that occurred along the island chain [Stauder, 1968b]. The slip angle measured clockwise on the fault plane from the strike direction, $\mathrm{N} 70^{\circ} \mathrm{W}$, is $41.4^{\circ}$. This means that the foot wall side (oceanic side) moved in about $\mathrm{N} 30^{\circ} \mathrm{W}$ direction with respect to the hanging wall side (continental side). This slip direction is more or less parallel to the slip directions determined for the 1964 Alaskan earthquake, 1963 Kurile Islands earthquake, and the 1968 Tokachi-Oki earthquake [Kanamori, 1971].

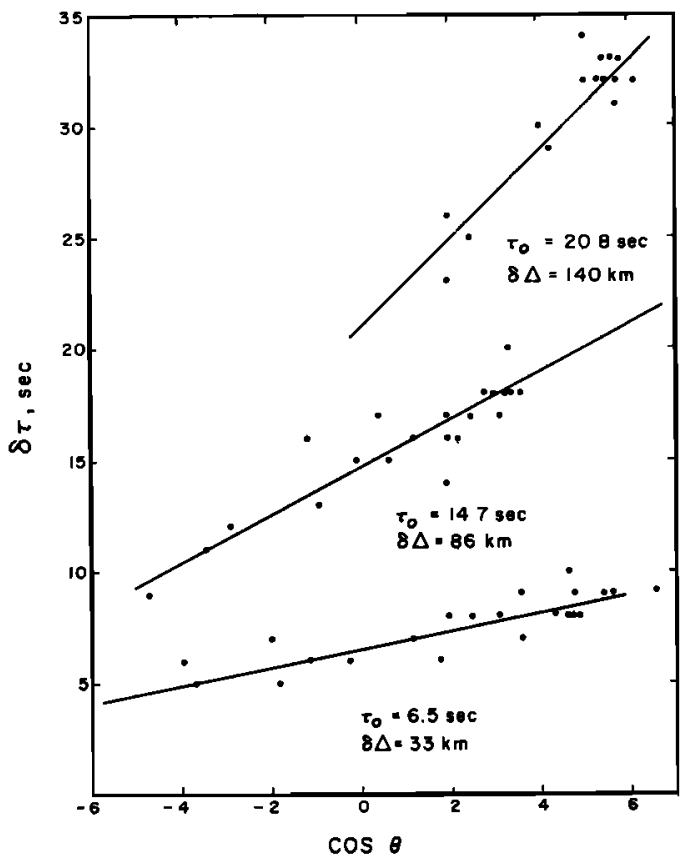

Fig, 4. Least squares lines for the solutions. Here $\theta$ is the angle between the line element $\Delta \Delta$ and the ray leaving the source for the station.

\section{Discussion}

It may seem that the conclusions from the studies above are contradictory. We have seen that, whereas the body wayes indicate not only a jerky propagation but also a southward propagation, the long-period surface waves show a smooth WNW propagation. These conclusions are not, however, inconsistent, for the multiple events in the initial $21 \mathrm{sec}$ are not necessarily related to the main propagation phase, which could have commenced simultaneously, and more smoothly, or 21 sec after the initial break. Because of the large amplitudes of the complex long-period $P$ waves, they were not recorded well on the WWSSN seismograms and hence were not subjected to study with the same tech-

TABLE 1. Multiple Events

\begin{tabular}{|c|c|c|c|c|c|c|c|}
\hline Event & $D$ & $\phi$ & $\varepsilon$ & $T_{0}$ & $\delta \Delta$ & $\underset{\frac{q}{6}}{\text { Error, }}$ & $\begin{array}{l}\text { Apparent } \\
\text { Velocity, } \\
\mathrm{km} / \mathrm{sec}\end{array}$ \\
\hline 1 & 6 & 200 & 1.1 & 6.5 & 33 & 18.3 & 5.1 \\
\hline 2 & -6 & 165 & 1.2 & 14.7 & 86 & 10.4 & 5.9 \\
\hline 3 & 15 & 140 & 1.7 & 20.8 & 140 & 21.6 & 6.7 \\
\hline
\end{tabular}


Wu and Kanamori: Rat Island Earthquake

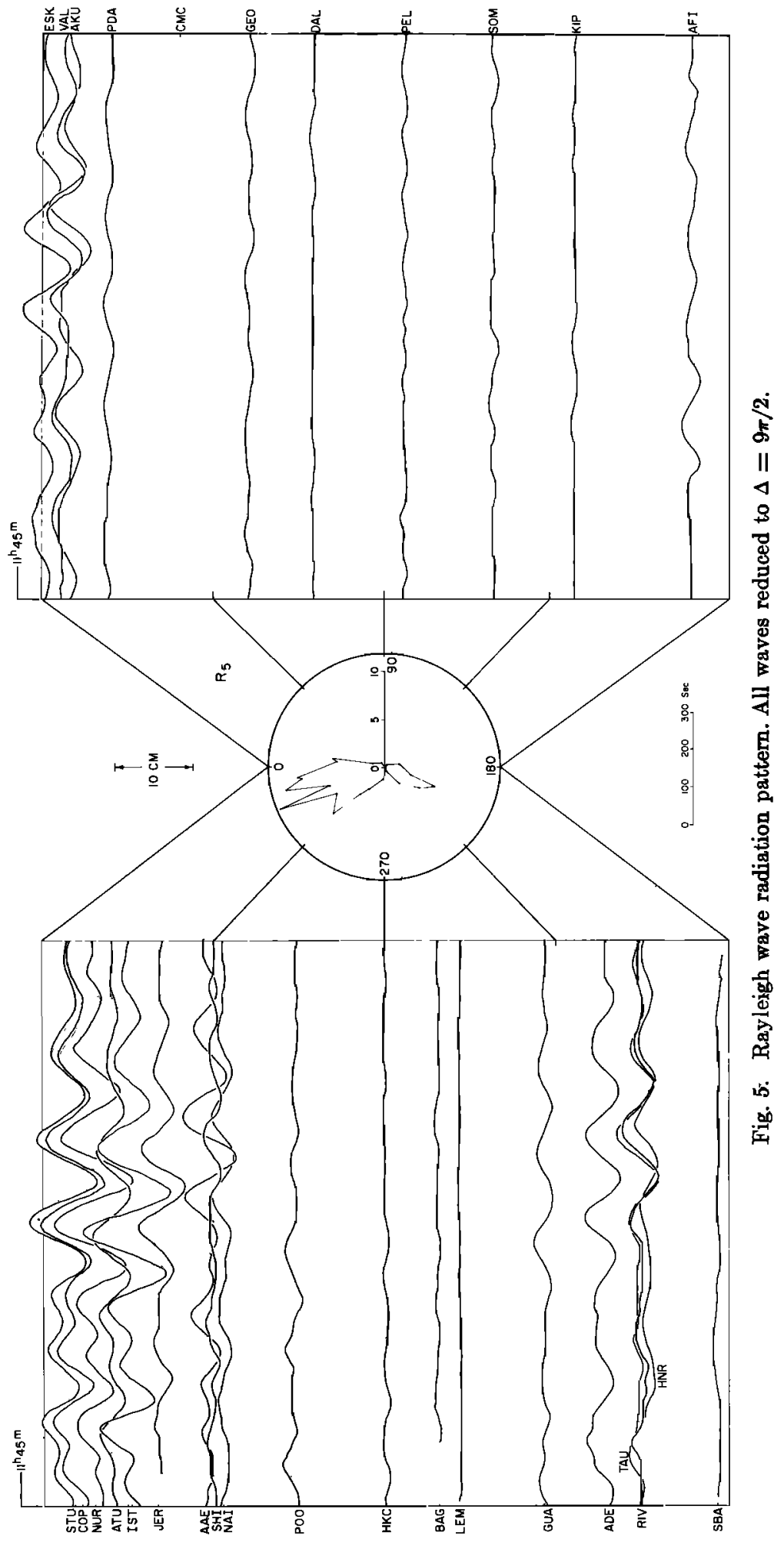




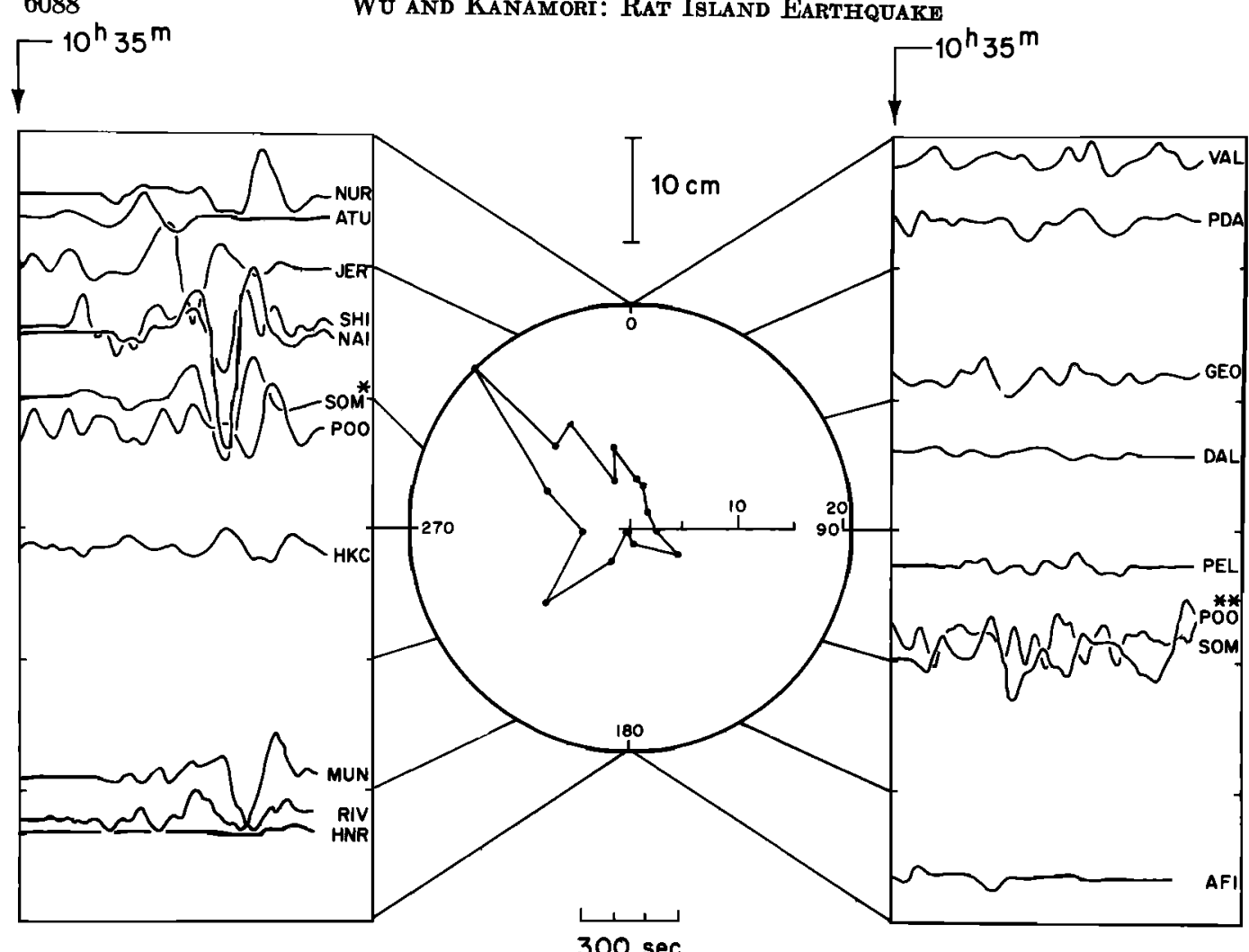

$300 \mathrm{sec}$

Fig. 6. Love wave radiation pattern. All waves reduced to $\Delta=9 \pi / 2$.

nique. These waves could have their sources lying along the path of propagation as delineated by the surface wave method. That the 150- to 300-8ec surface waves do not reveal the same information as the body waves is only natural, since these waves cannot discern behavior of short duration. Therefore from the surface waves we can deduce only the average velocity of rupture propagation together with the rupture length but not the possible accelerations and decelerations with a time scale of perhaps 50 sec or less.

The multiple-event nature of large earthquakes makes the meaning of the magnitude ambiguous. If $M_{L}$ is used, then, depending on the proximity of the station to a particular section of the fault, the magnitude will reflect the characteristics of that section, since by definition $M_{\mathrm{L}}$ is determined by the maximum recorded motion of a part of the seismogram and the nearest section of a fault is likely to contribute most of the energy owing to the near-field effect. If $m_{b}$ is used, however, the sit- uation is more serious, because here only the first few cycles of the $P$ wave (or other phases) are used. As we have mentioned before, the USCGS $m_{b}$ for the Rat Island mainshock was only 6.0 (USCGS Seismological Bulletin MSI 290 ), which implies that the energy of this earthquake is less than about $1 / 100,000$ that of the 1964 Alaskan earthquake and about 1/ 100,000 that of the 1963 Kurile earthquake [Gutenberg, 1956]. From the seismic moment it is clear that the Rat Island earthquake is smaller than the Alaskan earthquake, but not by 100,000 times in energy, and in fact is slightly larger than the 1963 Kurile earthquake. If the magnitude is to represent the total energy of the earthquake, an appropriate sum of magnitudes of the individual events should be used.

The idea of multiple events has been proposed by seismologists for several large shallow earthquakes [Wyss and Brune, 1967; Florensov and Solonenko, 1963], for one deep earthquake [Fukao, 1972], and even for earthquakes of magnitudes around 6 [Wu, 1968; Niazi, 1969]. Conceptually, 


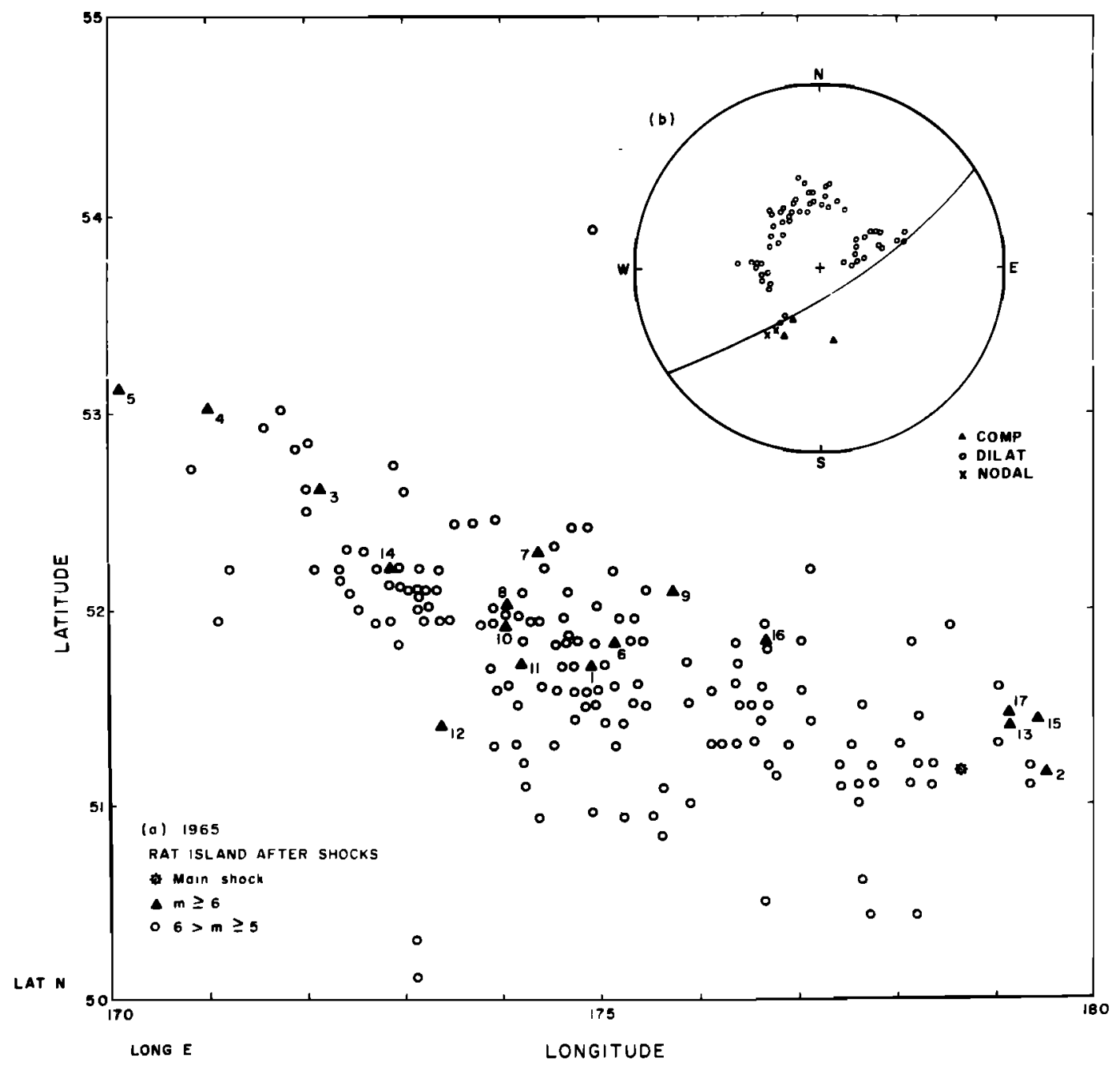

Fig. 7. (a) Large aftershocks. Numbers attached to the solid triangles mark the time sequence of events with $m_{b} \geq 6$ (from USCGS Preliminary Determination of Epicenters). (b) Stauder's partial solution for the main shock.

there are two ways to view multiple events in terms of source space and time functions. One is that the time function at each point is uniform but consists of a delayed sum of ramps (Figure $9 a$ ). This ramp could propagate with a uniform velocity. At each instant along the fault there will be a number of active sections corresponding to the accelerating and decelerating parts of the ramp (Figure $9 b$ ). The other possibility is that a propagating dislocation has a changing density function; i.e., $\mathbf{B}(\xi)$, the Burgers vector [Weertman, 1969 ], is also a function of $x$, the coordinate along the fault, $\mathbf{B}^{*}(\xi, x)$, or a function of time $t$,
$\mathbf{B}^{* *}(\xi, t)$ (Figures $\left.9 c, d\right)$. In this case there are 'dead' sections along the fault during the main propagation phase, and aftershock could occur at these places. In reality it is highly possible that both modes occur during the main shock of the Rat Island series.

If the earthquake is composed simply of a propagating rupture, the durations of $P$ waves in different azimuthal directions would be different. Thus in the direction of propagation at large distance we would expect a duration of about $100 \mathrm{sec}$ and in the opposite direction of about 150 sec. But on actual short-period 
seismograms for the Rat Island earthquake we do not see such a variation. The $P$ waves in all azimuths have decaying tails of about the same length. Thus a sequence of aftershocks occurring behind the main propagating dislocation line accompanies the main propagation, and the number of these aftershocks decreases exponentially as a function of time.

For shallow large earthquakes behind the trench, body wave focal mechanisms usually fail to give a complete solution [Stauder, 1968a] because of the lack of readable close-in records, and hence it is difficult to determine a shallow dipping plane. When they are combined with the surface wave method, however, the parameters for this plane can be estimated. Stauder $[1968 a, b]$ has shown that in the Aleutian Island chain the events with thrust mechanisms all have very similar high-angle planes. For the 1965 Rat Island series the same is true. All these events show a NE-SW strike and a southward dip of about $75^{\circ}$. That this plane cannot be the fault plane for the main shock is established by looking at the asymmetry of the Rayleigh and Love wave radiation patterns, which imply a NW rupture propagation direction. Since the NE-SW plane is steep and dipping south, a nonstrike NW direction of propagation is unreasonable, unless small segments of the fault line up en echelon; however, the continuous trench and the shape of the island arc do not agree with such geometry. BenMenahem and Rosenman [1972] adopted a high-angle solution for their interpretation of this earthquake; the strike of the plane is not consistent with Stauder's [1968a] solutions for earthquakes in this region. Stauder [1968a] also showed that the shallow plane dips about $15^{\circ}-20^{\circ}$ in the direction of $\mathrm{N} 50^{\circ} \mathrm{W}-\mathrm{N} 90^{\circ} \mathrm{W}$ for most of the thrust events in the aftershock series. By using a shallow-angle plane consistent with the partial solution of the main shock, we found that the direction of propagation has to deviate slightly from the strike. However, since the dip is shallow, the $10^{\circ}$ or so deviation only implies a dip direction propagation of about $85 \mathrm{~km}$, which could be accommodated very well by the width of the fault plane. The same sort of deviation has been observed for the 1964 Alaskan earthquake [Kanamori, 1970b].

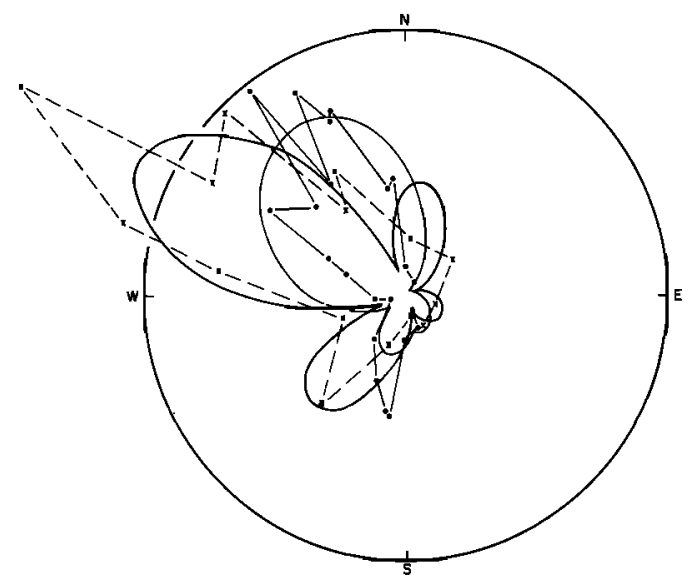

Fig. 8a. Preferred fit of the long-period surface wave data. Thin line represents theoretical Rayleigh wave data; heavy line, theoretical Love wave data; solid circles, observed Rayleigh wave data; crosses, observed Love wave data.

Both the $P$ wave and the surface wave results yield rupture velocities. The multiple events imply velocities of $5.1-6.7 \mathrm{~km} / \mathrm{sec}$ ( Table 1). These values are higher than those of shear wave velocity and approach those of

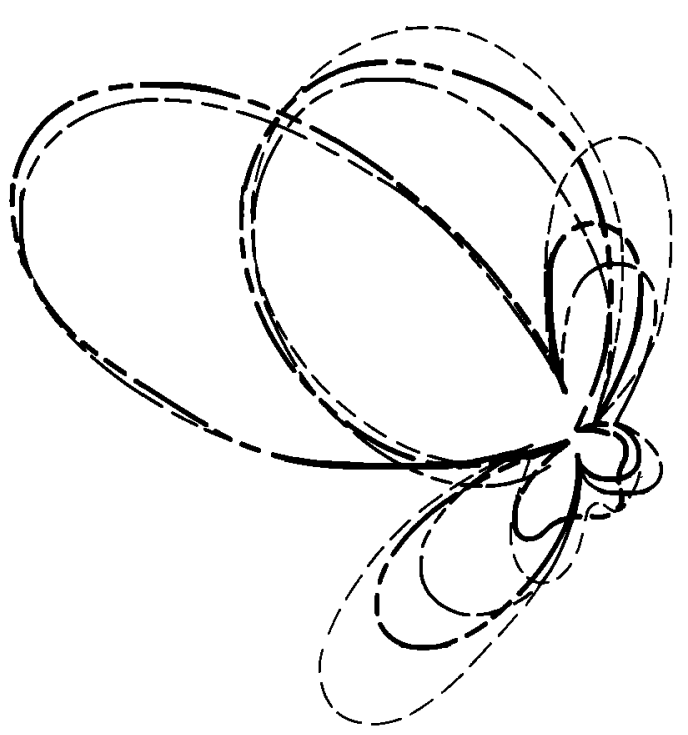

Fig. 8b. Other rupture velocities. Calculated radiation patterns with rupture velocities of $3.0\left(R_{1}, L_{1}\right.$; heavy dashed line), $3.5\left(R_{2}, L_{2}\right.$; medium dashed line), and $5 \mathrm{~km} / \mathrm{sec}\left(R_{s}, L_{s}\right.$; thin dached line). 

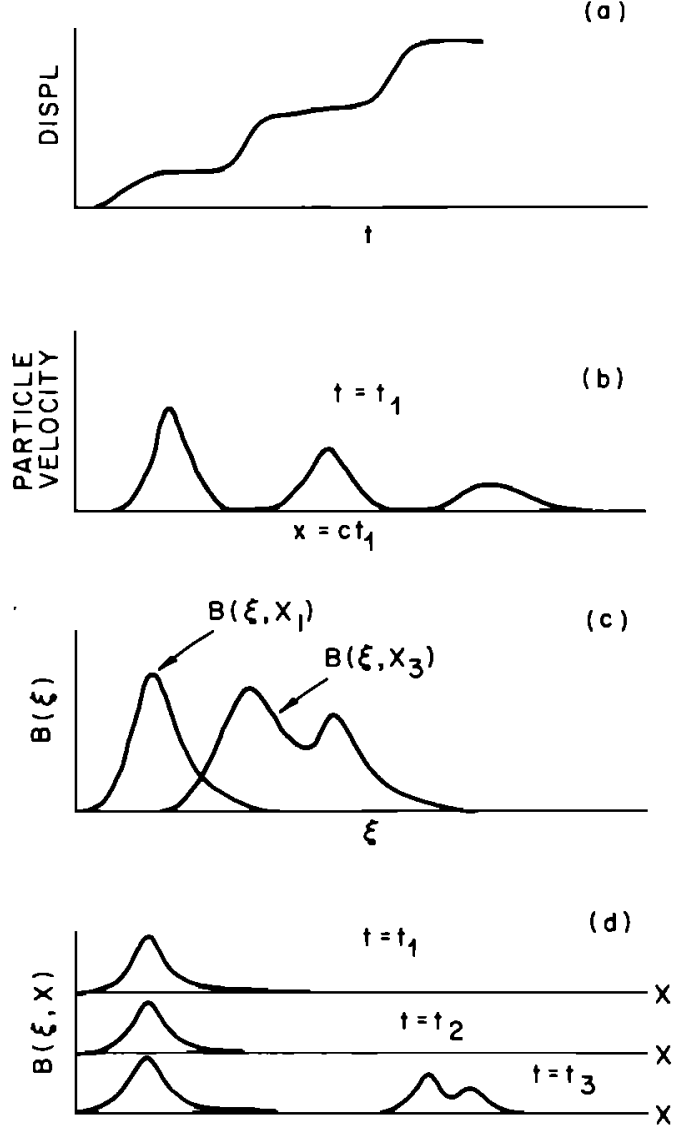

Fig. 9. Generation of multiple-event type of seismograms. (a) Displacement of a point along the fault. (b) Particle velocity function along the fault at $t=t$ for uniform propagating fault. This function will move down the line as $t$ increases. (c) Burgers vector as a function of $\xi$ and $x, \mathbf{B}\left(\xi, x_{2}\right) \equiv 0$. (d) Dislocation along the fault at different $t$.

compressional waves. Recently, such values have been observed in the laboratory [Wu et al., 1972; Johnson et al., 1973] and attained theoretically (R. Burridge, personal communication, 1973). In both instances, a low frictional coefficient is deemed responsible. For the experiments, low friction was achieved through accelerating creep; it is conceivable that this explanation is also applicable in real faulting.

The surface wave results indicate an average value of $4 \mathrm{~km} / \mathrm{sec}$ for the whole fault. In view of the complex process in the source region, the meaning of this value deserves further consideration.
Finally, it should be noted that the parallelism of the slip vectors for major earthquakes in the northern Pacific is conformable to the Pacific basin's moving as a rigid plate [McKenzie and Parker, 1967].

\section{REFERENCES}

Ben-Menahem, A., and M. Rosenman, Amplitude patterns of tsunami waves from submarine earthquakes, J. Geophys. Res., 77, 3097-3128, 1972.

Florensov, N. A., and V. P. Solonenko, The GobiAltai earthquake, Izd. Akad. Nauk SSR, 1963. (English translation by Israel Program for Scientific Translations, p. 392, 1965.)

Fukao, Y., Source process of a large deep-focus earthquake and its tectonic implications-The western Brazil earthquake of 1963, Phys. Earth Planet. Interiors, 5, 61-76, 1972.

Gutenberg, B., The energy of earthquakes, Quart. J. Geol. Soc. London, 112, 1-14, 1956.

Johnson, T., F. T. Wu, and C. H. Scholz, Source parameters for stick-slip and for earthquakes, Science, 179, 278-279, 1973.

Kanamori, H., Synthesis of long-period surface waves and its applications to earthquake source studies-Kurile Islands earthquake of October 13, 1963, J. Geophys. Res., 76, 5011-5028, 1970a.

Kanamori, $H$., The Alaskan earthquake of 1964: Radiation of long-period surface waves and source mechanism, J. Geophys. Res., 75, 5029$5040,1970 b$.

Kanamori, H., Focal mechanism of Tokachi-Oki earthquake of May 16, 1968, Tectonophysics, 12, 1-13, 1971.

Knopoff, L., Energy release in earthquakes, Geophys. J., 1, 44-52, 1958.

McKenzie, D. P., and R. L. Parker, The North Pacific: An example of tectonics on a sphere, Nature, 216, 1276-1280, 1967.

Niazi, M., Source dynamics of the Daslit-e Bayaz earthquake of August 31, 1968, Bull. Seismol. Soc. Amer., 69, 1843-1861, 1969.

Nowroozi, A. A., Terrestrial spectroscopy following the Rat Island earthquake, Bull. Seismol. Soc. Amer., 66, 1269-1288, 1966.

Stauder, W., Tensional character of earthquake foci beneath the Aleutian trench with relation to sea floor spreading, J. Geophys. Res., 73, 76937701,1968 .

Stauder, W., Mechanism of the Rat Island earthquake sequence of February 4, 1965, with relation to island ares and sea floor spreading, J. Geophys. Res., 78, 3847-3858, $1968 b$.

Wu, F. T., Parkfield earthquake of June 28, 1966 : Magnitude and source mechanism, Bull. Seismol. Soc. Amer., 58, 689-709, 1968.

Wu, F. T., K. C. Thomson, and H. Kuenzler, Stick-slip propagation velocity and seismic source mechanism, Bull. Seismol. Soc. Amer., in press, 1972. 
Weertman, J., Dislocation motion on an interface with friction that is dependent on sliding velocity, J. Geophys. Res., 74, 6617-6622, 1969.

Wyss, M., and J. N. Brune, The Alaskan earthquake of March 28, 1964, a complex multiple structure, Bull. Seismol. Soc. Amer., 57, 10171023,1967 .

(Received June 26, 1972;

revised May 16, 1973.) 